\title{
Anti-inflammatory diet consumption reduced fatty liver indices: Finding from a large cohort study in the Kurdish population
}

\section{Mitra Darbandi}

Kermanshah University of Medical Sciences

\section{Behrooz Hamzeh}

Kermanshah University of Medical Sciences

\section{Azad Ayenepour}

Kermanshah University of Medical Sciences

\section{Shahab Rezaeian}

Kermanshah University of Medical Sciences

\section{Farid Najafi}

Kermanshah University of Medical Sciences

\section{Ebrahim Shakiba}

Kermanshah University of Medical Sciences

\section{Yahya Pasdar ( $\square$ Yahya.pasdar@kums.ac.ir)}

Kermanshah University of Medical Sciences https://orcid.org/0000-0001-8682-5721

\section{Research}

Keywords: Dietary inflammatory index, Fatty liver index, Non-alcoholic fatty liver disease

Posted Date: December 21st, 2020

DOl: https://doi.org/10.21203/rs.3.rs-130173/v1

License: (9) (i) This work is licensed under a Creative Commons Attribution 4.0 International License. Read Full License 


\section{Abstract \\ Background}

The aim of this study was the assess association between of dietary inflammatory index (DII) and noninvasive markers of liver status in adults.

\section{Methods}

This cross-sectional study was performed on 8,520 individuals aged 35-65 years, recruited in Ravansar Non-Communicable Diseases (RaNCD) cohort study, the west of Iran. DII score was calculated based on participants' dietary intakes obtained from Food Frequency Questionnaire (FFQ). Fatty Liver Index (FLI) score was calculated by anthropometric measurements and some non-invasive markers of liver status. Linear regression models were used to estimate the associations and adjust for possible confounding factors.

\section{Results}

The mean of age was $47.24 \pm 8.31$ years and 4275 (\%50.18) were male. A greater DIl score was significantly associated with higher energy intake, BMI (body mass index), BFM (body fat mass), blood pressure and FLI $(P<0.001)$. Participants with the highest DII score had a significantly higher consumption saturated fat, trans fat and red meat than those in the lowest quartile $(P<0.001)$. With one point increment in the physical activity, on average the risk of having FLI decreased by $5(95 \% \mathrm{Cl},-0.484$ to -0.519). After adjustment for age and sex, participants in the highest quartile of DII score had a greater risk of FLI ( $\beta$ : $0.742,95 \% \mathrm{Cl}: 0.254,0.601)$.

\section{Conclusion}

The more pro-inflammatory diet in participants was associated with higher FLI; DII score was positively associated with non-invasive liver markers (ALT, AST and GGT). FLI had positive association with BMI, WC, BFM and energy intake. Thus having an anti-inflammatory diet can help balance liver enzymes, reduce obesity and fatty liver.

\section{Background}

Non-alcoholic fatty liver disease (NAFLD) is defined as the presence of $\geq 5 \%$ of hepatic steatosis without significant alcohol consumption [1]. NAFLD is the most common form of chronic liver disease worldwide that is the growing cause of end-stage liver disease. NAFLD recognized that contribute in the hepatocellular cancer ( $\mathrm{HCC}$ ) etiology [2], and its prevalence is about $17-35 \%$ in worldwide [3]. In recent decades, lifestyle changes including changes in habits and diet, decreased physical activity and 
increased prevalence of obesity have led to increase in the prevalence of NAFLD [2]. Third of western populations has NAFLD [4]. Among the mentioned risk factors, one of the markers of NAFLD in the progressive stages is inflammation [5]. On the other hand different studies show that diet can modulate inflammatory status [6], So the evaluation of inflammatory potential of diet can be useful for the study of association between diet and fatty liver. Today use of different dietary indexes is the common tool to study the association of diet quality and pathologic status including fatty liver disease [7].

It has been proved, some diets such as Western-like diets have a strong pro-inflammatory potential [8]. Dietary inflammatory index (DII) is a useful and interesting tool that has been developed and validated to evaluation the inflammatory potential of the overall diet [9]. Several studies have shown that DII is associated with diseases including metabolic syndrome, cancer and cardiovascular disease (CVD) [1012]. A study by Cantero et al. Showed that a pro-inflammatory diet may contribute to the development of fatty liver [13].

Recently, a number of indices have been considered to predict fatty changes of the liver including the fatty liver index (FLI), hepatic steatosis index (HIS) and NASH Score, and Steato test (ST) [14-16]. FLI developed by Bedogni et al. in 2006, is an equation includes body mass index (BMI), waist circumference (WC), triglycerides (TG), and Gamma-Gluteamyl transferase (GGT) to predict fatty liver [14], that is easy to use because each of its components is a common clinical measurement, this index has been validated as a practical, reliable and economical tool for diagnosing NAFLD in large epidemiological studies [17]. Studies have shown that FLI is an accurate alternative marker of hepatic steatosis in Asian and Western populations $[18,19]$. A study by Huang, $X$ et al. (2015) examined the validity of FLI and showed that it can accurately detect NAFLD with a good AUROC of 0.83 in middle-aged and elderly [20] and Dehnavi $Z$ et al. (2017) the AUC of FLI reported 0.85 in the diagnosis of NAFLD [21]. Therefore, the present study evaluated associations of a validated DII, as a tool to assess the inflammatory capacity of the diet with non-invasive liver markers in adults from the Ravansar Non-Communicable Diseases (RaNCD) cohort study.

\section{Methods}

\section{Study Population}

This is a cross-sectional study based on baseline data from Ravansar Non-Communicable disease (RaNCD) prospective study in western Iran in 2020. The RaNCD study is part of a prospective epidemiological research study in Iran (PERSIAN). Ravansar is a district with urban and rural areas which is located in the west of Iran and in Kermanshah province with a population of about 50,000 . The initial phase data was collected in 2014, and 10,000 adults between the ages of 35 and 65, who were registered as permanent residents of Ravansar were included in this cohort study. RaNCD study methodology and design with details have been published in 2019 [22]. Participants included all subjects from the first phase of the RaNCD study. For this study, the exclusion criteria were as follows: pregnancy, chronic 
diseases such as hepatitis B, hepatitis C, cancer, thyroid disorder and the case that their information was incomplete.

\section{Data Collection}

Data collection and all measurements of anthropometry and biochemical were conducted and assessed in the RaNCD cohort site. Participants were invited to the cohort center and the questionnaires were completed by trained experts. Demographic information and personal habits were completed face-to-face in the digital cohort questionnaire.

\section{Anthropometry Measurements}

We used the Bio-Impedance Analyzer BIA (Inbody 770, Inbody Co, Seoul, Korea) to measure body weight with a precision of $0.5 \mathrm{~kg}$ and BSM 370 (Biospace Co, Seoul, Korea) to measure height with the precision of $0.1 \mathrm{~cm}$. Body composition components including BMI, Body fat mass (BFM), visceral fat area (VFA), Waist hip ratio (WHR) and WC were measured by BIA. WC also was measured with a flexible measuring tape at a level midway between the lowest rib margin and the iliac crest.

\section{Biochemical Factors}

For collection of the blood sample, serum concentrations of liver enzymes and lipid profiles were measured after 8-12 hours of fasting.

\section{Blood Pressure}

We measured blood pressure using a manometer cuff and stethoscope from both arm in the seated position and after 10 minutes of rest for two times from each arm with an interval of 5 minutes. Then a mean of both systolic and diastolic blood pressure was reported.

\section{Fatty Liver Index}

FLI was first introduced by Bedogni et al. in 2006 using the bootstrapped stepwise logistic regression analysis [14], with thirteen variables (including gender, age, ethanol intake, Alanine aminotransferase (ALT), Aspartate transaminase (AST), GGT, BMI, WC, sum of four skinfolds, glucose, insulin, TG and cholesterol) that 4 variables remained as predictors in the equation:

FLI= [e 0.953x $\log (e)(T G)+0.139 \times \mathrm{BMI}+0.718 \times \log (\mathrm{e})(\mathrm{GGT})+0.053 \times \mathrm{WC}-15.745] /[$ [ $1+\mathrm{e} 0.953 \times$ $\log (e)(T G)+0.139 \times B M I+0.718 \times \log (e)(G G T)+0.053 \times W C-15.745] \times 100$.

The accuracy measured with area under the receiver operator characteristic curve (AUROC) of the FLI was 0.83 (95\% Cl: 0.825 to 0.842$)$ in detecting fatty liver [20]. The FLI ranges from 0 to 100 . Thus FLI scores of $<30$ and $\mathrm{FLI} \geq 60$ indicated the absence or presence, respectively, in fatty liver with a good diagnostic accuracy [14]. 


\section{Assessment of DII}

Dietary information derived from the Food Frequency Questionnaire (FFQ) was used to calculate DII scores for subjects. Shivappa et al. found that 45 foods items were associated with one or more of the inflammatory including Interleukin-1b (IL-1b), Interleukin- 6 (IL-6), Tumor Necrosis Factor-a (TNF-a) or Creactive protein (CRP) or anti-inflammatory markers including Interleukin-4 (IL-4) and Interleukin-10 (IL10). They scored the inflammatory potential for each food parameter according to whether it increased inflammatory or decreased anti-inflammatory markers $(+1)$, or it decreased inflammatory or increased anti-inflammatory markers $(-1)$, or had no effect $(0)$ on the level of inflammatory or anti-inflammatory markers. They calculated global mean and standard deviation for each of the 45 food parameters based on 11 data sets from 11 countries in different parts of the world [9].

In the present study, according to the food parameters in the Iranian questionnaire, we calculated DII score based on 31 food parameters, foods and nutrients that we were able to use in this study as follow: vitamin A, vitamin B6, vitamin B12, vitamin C, vitamin D, vitamin E, folic acid, niacin, iron, zinc, selenium, magnesium, beta-carotene, caffeine, thiamin, riboflavin, onion, garlic, tea, omega-3, omega- 6 , trans fat, saturated fats (SFAs), cholesterol, mono-unsaturated fatty acids (MUFA), poly-unsaturated fatty acids (PUFA), fiber, protein, total fat, carbohydrate and energy.

To calculate DII score for each subject, we subtracted the "standard global average" from the value consumed per person and then divided by the "global standard deviation" to obtain the Zscore for each food parameter. We used the global means \pm SDs from the Shivappa et al. study [9]. Then we converted these values to a centered percentiles score to minimize the risk of skewness. The inflammatory score for each of the food parameters was calculated by this method, and then the inflammatory score of all parameters was summed to calculate the overall DII score; that this score could be positive or negative. The more positive DII scores indicate more pro-inflammatory diets and more negative scores imply more inti-inflammatory diets $[9,23]$.

\section{Statistical Analysis}

All analyzes in this study were performed using Stata version 14.1 software (Stata Corp, College Station, TX, USA). General characteristics, anthropometric indices and biochemical factors of participants across quartiles of DII score were reported as mean \pm standard deviation for continuous variables and as percentages for qualitative variables. The normality was checked using the Kolmogorov-Smirnov test. To comparisons of differences across DII quartiles, we used one-way ANOVA test. Analysis of linear regression was used to determine associations between DII score and $\mathrm{FLI}$, anthropometric indices adjusted for the following confounding factors: age, sex, total energy, smoking, alcohol use and physical activity. Variables with p-value $<0.2$ in univariable analysis were entered into multivariable linear model. For statistical analyses, a p-value of $<0.05$ with $95 \%$ confidence intervals (Cls) was considered significant.

\section{Results}


After applying the exclusion criteria among 10,063 participants, 8520 participants with mean age of $47.24 \pm 8.31$ years were studied. Overall $4275(\% 50.18)$ were male, $1042(\% 23.06)$ were current smoker and 564 (\%6.62) were alcohol consumed. The average of DII score was $-2.32 \pm 1.61$ with a range of -6.18 to 4.27. In the study population, the average of FLI was $87.80 \pm 3.99$ with a range of 19.35 to 94.16 .

Compared with those in the lowest quartile, participants in the highest quartile of DII score were younger $(\mathrm{P}<0.001)$ and had a lower percentage of current smokers (Q1=\%23.06 VS. Q4=\%18.82, $\mathrm{P}<0.001)$. A greater DII score was significantly associated with consumption of alcohol $(P<0.001)$. There were significant differences in BMI, SBP, DBP, FLI, TG, BFM, ALT and ALT/AST across quartiles of DIl score. No significant differences were found in WC and VFA across quartiles of DII score (Table 1). 
Table 1

Baseline characteristics, anthropometric and biochemical of participant's factors according to the dietary inflammatory index score

\begin{tabular}{|c|c|c|c|c|c|c|}
\hline \multirow[t]{2}{*}{ Variables } & \multicolumn{6}{|c|}{ Quartiles of Dietary Inflammatory Index (DII) } \\
\hline & Total & Q1 & Q2 & Q3 & Q4 & $\begin{array}{l}\mathrm{P} \\
\text { value* }\end{array}$ \\
\hline Frequency & 8520 & 2124 & 2089 & 2121 & 2186 & - \\
\hline $\begin{array}{l}\text { Dll score, } \\
\text { Mean } \pm S D\end{array}$ & $-2.32 \pm 1.61$ & $-4.04 \pm 0.41$ & $-3.13 \pm 0.25$ & $\begin{array}{l}-2.10 \pm \\
0.38\end{array}$ & $-0.08 \pm 1.05$ & - \\
\hline Age (year) & $\begin{array}{l}47.24 \pm \\
8.31\end{array}$ & $\begin{array}{l}48.85 \pm \\
8.52\end{array}$ & $\begin{array}{l}47.42 \pm \\
8.34\end{array}$ & $\begin{array}{l}46.59 \pm \\
8.17\end{array}$ & $\begin{array}{l}46.13 \pm \\
7.98\end{array}$ & $\begin{array}{l}< \\
0.001\end{array}$ \\
\hline Sex (\% male) & $\begin{array}{l}4275 \\
(50.18)\end{array}$ & $888(20.77)$ & $966(22.60)$ & $\begin{array}{l}1098 \\
(25.68)\end{array}$ & $\begin{array}{l}1323 \\
(30.95)\end{array}$ & $<.001$ \\
\hline $\begin{array}{l}\text { Current smoker, } \\
\mathrm{n}(\%)\end{array}$ & $\begin{array}{l}1042 \\
(23.06)\end{array}$ & $233(30.14)$ & $255(27.04)$ & $\begin{array}{l}254 \\
(21.01)\end{array}$ & $300(18.82)$ & $\begin{array}{l}< \\
0.001\end{array}$ \\
\hline $\begin{array}{l}\text { Use alcohol, n } \\
\text { (\%) }\end{array}$ & $564(6.62)$ & $103(4.85)$ & $115(5.51)$ & $143(6.74)$ & $203(9.29)$ & $<.001$ \\
\hline Weight (kg) & $\begin{array}{l}73.07 \pm \\
13.67\end{array}$ & $\begin{array}{l}70.10 \pm \\
13.42\end{array}$ & $\begin{array}{l}72.26 \pm \\
13.27\end{array}$ & $\begin{array}{l}73.77 \pm \\
13.63\end{array}$ & $\begin{array}{l}76.05 \pm \\
13.67\end{array}$ & $<.001$ \\
\hline $\mathrm{BMI}\left(\mathrm{kg} / \mathrm{m}^{2}\right)$ & $\begin{array}{l}27.44 \pm \\
4.60\end{array}$ & $\begin{array}{l}26.97 \pm \\
4.62\end{array}$ & $\begin{array}{l}27.35 \pm \\
4.60\end{array}$ & $\begin{array}{l}27.53 \pm \\
4.63\end{array}$ & $\begin{array}{l}27.90 \pm \\
4.54\end{array}$ & $\begin{array}{l}< \\
0.001\end{array}$ \\
\hline $\mathrm{BFM}(\mathrm{kg})$ & $\begin{array}{l}33.47 \pm \\
9.52\end{array}$ & $\begin{array}{l}24.22 \pm \\
9.22\end{array}$ & $\begin{array}{l}24.90 \pm \\
9.56\end{array}$ & $\begin{array}{l}25.12 \pm \\
9.66\end{array}$ & $\begin{array}{l}25.26 \pm \\
9.72\end{array}$ & $<.001$ \\
\hline WHR & $0.94 \pm 0.06$ & $0.93 \pm 0.06$ & $0.94 \pm 0.06$ & $0.94 \pm 0.06$ & $0.94 \pm 0.06$ & $<.001$ \\
\hline WC $(\mathrm{cm})$ & $\begin{array}{l}97.10 \pm \\
10.51\end{array}$ & $\begin{array}{l}97.10 \pm \\
10.84\end{array}$ & $\begin{array}{l}97.28 \pm \\
10.34\end{array}$ & $\begin{array}{l}97.25 \pm \\
10.45\end{array}$ & $\begin{array}{l}96.75 \pm \\
10.37\end{array}$ & 0.328 \\
\hline VFA & $\begin{array}{l}120.92 \pm \\
51.51\end{array}$ & $\begin{array}{l}119.29 \pm \\
50.70\end{array}$ & $121 \pm 51.65$ & $\begin{array}{l}121.80 \pm \\
51.86\end{array}$ & $\begin{array}{l}121.08 \pm \\
51.80\end{array}$ & 0.386 \\
\hline $\mathrm{TG}(\mathrm{mg} / \mathrm{dl})$ & $\begin{array}{l}138.64 \pm \\
85.58\end{array}$ & $\begin{array}{l}135.40 \pm \\
82.90\end{array}$ & $\begin{array}{l}136.51 \pm \\
79.61\end{array}$ & $\begin{array}{l}138.33 \pm \\
83.36\end{array}$ & $\begin{array}{l}144.11 \pm \\
95.06\end{array}$ & 0.004 \\
\hline AST (UI/L) & $\begin{array}{l}21.51 \pm \\
8.88\end{array}$ & $\begin{array}{l}21.34 \pm \\
7.97\end{array}$ & $\begin{array}{l}21.39 \pm \\
8.40\end{array}$ & $\begin{array}{l}21.40 \pm \\
8.33\end{array}$ & $\begin{array}{l}21.88 \pm \\
10.52\end{array}$ & 0.161 \\
\hline ALT (UI/L) & $\begin{array}{l}25.04 \pm \\
14.73\end{array}$ & $\begin{array}{l}23.23 \pm \\
13.18\end{array}$ & $\begin{array}{l}24.21 \pm \\
14.25\end{array}$ & $\begin{array}{l}25.69 \pm \\
15.31\end{array}$ & $\begin{array}{l}26.95 \pm \\
15.76\end{array}$ & $<.001$ \\
\hline AST/ALT & $0.96 \pm 0.34$ & $1.02 \pm 0.33$ & $0.98 \pm 0.38$ & $0.93 \pm 0.32$ & $0.90 \pm 0.28$ & $\begin{array}{l}<.001 \\
0.001\end{array}$ \\
\hline GGT (UI/L) & $\begin{array}{l}361.40 \pm \\
262.39\end{array}$ & $\begin{array}{l}350.58 \pm \\
261.90\end{array}$ & $\begin{array}{l}360.99 \pm \\
268.67\end{array}$ & $\begin{array}{l}363.83 \pm \\
63.16\end{array}$ & $\begin{array}{l}369.92 \pm \\
255.79\end{array}$ & 0.106 \\
\hline
\end{tabular}


Table 2

Description of food parameters participants according to the dietary inflammatory index score

\begin{tabular}{|c|c|c|c|c|c|c|}
\hline $\begin{array}{l}\text { Food } \\
\text { parameters }\end{array}$ & Total & Q1 & Q2 & Q3 & Q4 & $\begin{array}{l}P \\
\text { value }\end{array}$ \\
\hline $\begin{array}{l}\text { Energy } \\
\text { (kcal/d) }\end{array}$ & $\begin{array}{l}2328.53 \pm \\
935.00\end{array}$ & $\begin{array}{l}1935.18 \pm \\
706.80\end{array}$ & $\begin{array}{l}2081.70 \pm \\
731.33\end{array}$ & $\begin{array}{l}2356.85 \pm \\
838.53\end{array}$ & $\begin{array}{l}2919.13 \pm \\
1082.31\end{array}$ & $\begin{array}{l}< \\
0.001\end{array}$ \\
\hline $\begin{array}{l}\text { Carbohydrate } \\
(\% \mathrm{E})\end{array}$ & $\begin{array}{l}64.57 \pm \\
8.04\end{array}$ & $\begin{array}{l}66.32 \pm \\
8.64\end{array}$ & $\begin{array}{l}65.53 \pm \\
7.47\end{array}$ & $\begin{array}{l}63.88 \pm \\
7.55\end{array}$ & $62.62 \pm 7.90$ & $\dot{0.001}$ \\
\hline Protein (\%E) & $\begin{array}{l}15.73 \pm \\
2.05\end{array}$ & $\begin{array}{l}14.93 \pm \\
1.70\end{array}$ & $\begin{array}{l}15.54 \pm \\
1.89\end{array}$ & $\begin{array}{l}15.81 \pm \\
1.92\end{array}$ & $16.59 \pm 2.30$ & $\dot{0.001}$ \\
\hline Lipid (\%E) & $\begin{array}{l}19.44 \pm \\
7.65\end{array}$ & $\begin{array}{l}18.10 \pm \\
8.43\end{array}$ & $\begin{array}{l}18.48 \pm \\
7.10\end{array}$ & $\begin{array}{l}20.11 \pm \\
7.24\end{array}$ & $21.01 \pm 7.38$ & $\begin{array}{l}<.001 \\
0.001\end{array}$ \\
\hline $\begin{array}{l}\text { Saturated fat } \\
(\mathrm{g} / \mathrm{d})\end{array}$ & $\begin{array}{l}20.38 \pm \\
14.72\end{array}$ & $\begin{array}{l}16.34 \pm \\
12.92\end{array}$ & $\begin{array}{l}16.83 \pm \\
11.64\end{array}$ & $\begin{array}{l}21.06 \pm \\
13.54\end{array}$ & $\begin{array}{l}27.03 \pm \\
17.39\end{array}$ & $\dot{0.001}$ \\
\hline MUFA (g/d) & $\begin{array}{l}13.44 \pm \\
12.26\end{array}$ & $9.89 \pm 9.85$ & $\begin{array}{l}10.77 \pm \\
9.29\end{array}$ & $\begin{array}{l}13.91 \pm \\
11.23\end{array}$ & $\begin{array}{l}18.97 \pm \\
15.39\end{array}$ & $\begin{array}{l}< \\
0.001\end{array}$ \\
\hline PUFA (g/d) & $4.10 \pm 2.55$ & $2.56 \pm 1.44$ & $3.27 \pm 1.45$ & $4.21 \pm 1.88$ & $6.26 \pm 03.22$ & $\dot{0} 001$ \\
\hline $\begin{array}{l}\text { Trans fat } \\
(\mathrm{g} / \mathrm{d})\end{array}$ & $0.06 \pm 0.08$ & $0.04 \pm 0.05$ & $0.05 \pm 0.05$ & $0.06 \pm 0.06$ & $0.10 \pm 0.11$ & $\begin{array}{l}< \\
0.001\end{array}$ \\
\hline $\begin{array}{l}\text { Cholesterol } \\
(\mathrm{mg} / \mathrm{d})\end{array}$ & $\begin{array}{l}259.11 \pm \\
163.28\end{array}$ & $\begin{array}{l}187.39 \pm \\
20.15\end{array}$ & $\begin{array}{l}219.57 \pm \\
19.60\end{array}$ & $\begin{array}{l}266.17 \pm \\
41.24\end{array}$ & $\begin{array}{l}359.73 \pm \\
200.56\end{array}$ & $\begin{array}{l}<.001 \\
0.00\end{array}$ \\
\hline $\begin{array}{l}\text { Red meat } \\
(\mathrm{g} / \mathrm{d})\end{array}$ & $0.78 \pm 1.15$ & $0.66 \pm 0.97$ & $0.62 \pm 0.92$ & $0.81 \pm 1.10$ & $1.03 \pm 1.47$ & $\begin{array}{l}< \\
0.001\end{array}$ \\
\hline Poultry (g/d) & $1.58 \pm 1.47$ & $1.03 \pm 0.87$ & $1.37 \pm 1.12$ & $1.63 \pm 1.41$ & $2.28 \pm 1.93$ & $\begin{array}{l}<.001 \\
0.001\end{array}$ \\
\hline Fish $(g / d)$ & $\begin{array}{l}0.19 \pm \\
0.304\end{array}$ & $0.56 \pm 0.15$ & $0.13 \pm 0.22$ & $0.20 \pm 0.28$ & $0.32 \pm 0.43$ & $\begin{array}{l}< \\
0.001\end{array}$ \\
\hline $\begin{array}{l}\text { Vegetables } \\
(\mathrm{g} / \mathrm{d})\end{array}$ & $4.86 \pm 3.52$ & $2.41 \pm 1.47$ & $3.61 \pm 1.90$ & $5.09 \pm 2.40$ & $8.23 \pm 4.30$ & $\begin{array}{l}<.001 \\
0.001\end{array}$ \\
\hline Fruits(g/d) & $2.57 \pm 2.22$ & $1.41 \pm 1.29$ & $1.96 \pm 1.46$ & $2.77 \pm 1.88$ & $4.10 \pm 2.86$ & $\dot{0.001}$ \\
\hline $\begin{array}{l}\text { Dairy product } \\
(\mathrm{g} / \mathrm{d})\end{array}$ & $2.90 \pm 2.25$ & $2.42 \pm 2.20$ & $2.50 \pm 1.95$ & $3.02 \pm 2.14$ & $3.63 \pm 2.48$ & $\begin{array}{l}<.001 \\
0.00\end{array}$ \\
\hline $\begin{array}{l}\text { Legumes } \\
(\mathrm{g} / \mathrm{d})\end{array}$ & $\begin{array}{l}2.86 \pm \\
2.720\end{array}$ & $1.46 \pm 1.14$ & $2.12 \pm 1.59$ & $2.89 \pm 2.13$ & $4.90 \pm 3.76$ & $\begin{array}{l}< \\
0.001\end{array}$ \\
\hline $\operatorname{Egg}(g / d)$ & $\begin{array}{l}0.37 \pm \\
0.367\end{array}$ & $0.25 \pm 0.28$ & $0.33 \pm 0.32$ & $0.38 \pm 0.34$ & $0.50 \pm 0.45$ & $\begin{array}{l}<.001 \\
0.001\end{array}$ \\
\hline
\end{tabular}




\begin{tabular}{|lllllll|}
\hline $\begin{array}{l}\text { Food } \\
\text { parameters }\end{array}$ & Total & Q1 & Q2 & Q3 & Q4 & $\begin{array}{l}\text { P } \\
\text { value }\end{array}$ \\
\hline Potato $(\mathrm{g} / \mathrm{d})$ & $0.52 \pm 0.48$ & $0.35 \pm 0.30$ & $0.46 \pm 0.38$ & $0.54 \pm 0.43$ & $0.74 \pm 0.64$ & $<$ \\
& & & & & \\
\hline $\begin{array}{l}\text { Refined } \\
\text { grains }(\mathrm{g} / \mathrm{d})\end{array}$ & $5.59 \pm 2.63$ & $4.87 \pm 1.90$ & $5.25 \pm 2.53$ & $5.65 \pm 2.49$ & $6.55 \pm 3.12$ & $<$ \\
\hline $\begin{array}{l}\text { Whole grains } \\
(\mathrm{g} / \mathrm{d})\end{array}$ & $0.75 \pm$ & $0.42 \pm 0.55$ & $0.57 \pm 0.67$ & $0.77 \pm 0.92$ & $1.24 \pm 1.39$ & $<$ \\
\hline Nuts $(\mathrm{g} / \mathrm{d})$ & $4.14 \pm 6.66$ & $1.91 \pm 3.53$ & $2.85 \pm 4.32$ & $4.36 \pm 6.10$ & $7.32 \pm 9.51$ & $<$ \\
\hline
\end{tabular}

Crude and multivariable-adjusted linear regression analysis was used to investigate the effect of some factors on FLI (Table 3). We found a significant association between DII scores and FLI, with one point increment in the DII score, on average the risk of having FLI increased by $13(95 \% \mathrm{Cl}, 0.076$ to 0.181$)$. In the crude and multivariable-adjusted model with one point increment in the physical activity, on average the risk of having FLI decreased by $6(95 \% \mathrm{Cl},-0.076$ to -0.056$)$ and $5(95 \% \mathrm{Cl},-0.063$ to -0.042$)$, respectively. We found a significant association between the $\mathrm{FLI}$ and $\mathrm{BMI}$, with one point increment in the $\mathrm{BMI}$, on average the risk of having FLI increased by 23 in the crude and 50 in the adjusted models.

Table 3

Linear regression analysis of association between dietary inflammatory index and fatty liver index

\begin{tabular}{|lllll|}
\hline FLI & Crude & \multicolumn{1}{l|}{ Adjusted* } & \\
\cline { 2 - 5 } & $\boldsymbol{\beta}(95 \% \mathrm{Cl})$ & P value & $\boldsymbol{\beta}(95 \% \mathrm{Cl})$ & P value \\
\hline Age (year) & $0.033(0.023,0.043)$ & $<0.001$ & $0.032(0.019,0.044)$ & $<0.001$ \\
\hline Sex & $-0.082(-0.252,0.087)$ & 0.111 & $-0.009(0.236,0.217)$ & 0.935 \\
\hline DII & $0.130(0.076,0.181)$ & $<0.001$ & $0.032(-0.027,0.092)$ & 0.293 \\
\hline Energy intake (kcal day) & $0.001(0.006,0.002)$ & 0.002 & $0.0001(0.000,0.000)$ & 0.011 \\
\hline BMI & $0.232(0.225,0.239)$ & $<0.001$ & $0.501(0.484,0.519)$ & $<0.001$ \\
\hline BFM & $0.232(0.225,0.240)$ & $<0.001$ & $0.221(0.212,0.230)$ & $<0.001$ \\
\hline WC & $0.237(0.231,0.243)$ & $<0.001$ & $0.221(0.214,0.230)$ & $<0.001$ \\
\hline Physical Activity & $-0.066(-0.076,-0.056)$ & $<0.001$ & $-0.052(-0.063,-0.042)$ & $<0.001$ \\
\hline *Adjusted for current smoker and use alcohol & & & \\
\hline
\end{tabular}

After adjustment for age and sex (Model 1, Table 4) and after adjustment for BMI, WC and physical activity (Model 2, Table 4), participants in the highest quartile of DII score had a greater risk of FLI ( $\beta$ : 0.742 and $\beta: 0.497$, respectively) than those in the lowest quartile. Figure 1 shows a positive association between DII and liver markers. 
Table 4

Linear regression analysis, association of between fatty liver index across quartiles of dietary inflammatory index

\begin{tabular}{|c|c|c|c|c|c|c|c|}
\hline & Quar & les of Dietary Inf & mmatory & ndex (DII) & & & \\
\hline & Q1 & Q2 & $P$ value & Q3 & $P$ value & Q4 & P value \\
\hline & & $\beta(95 \% \mathrm{Cl})$ & & $\beta(95 \% \mathrm{Cl})$ & & $\beta(95 \% \mathrm{Cl})$ & \\
\hline Crude & Ref. & 0.293 & 0.018 & 0.448 & $<0.001$ & 0.643 & $<0.001$ \\
\hline & & $(0.010, .336)$ & & $(0.032,0.3767)$ & & $(0.201,0.542)$ & \\
\hline Model 1 & Ref. & 0.345 & 0.005 & 0.532 & $<0.001$ & 0.742 & $<0.001$ \\
\hline & & $(-0.023,0.369)$ & & $(0.082,0.428)$ & & $(0.254,0.601)$ & \\
\hline Model 2 & Ref. & 0.177 & 0.058 & 0.294 & 0.002 & 0.497 & $<0.001$ \\
\hline & & $(-0.056,0.219)$ & & $(-0.043,0.232)$ & & $(0.116,0.393)$ & \\
\hline
\end{tabular}

\section{Discussion}

Our study findings showed that a higher pro-inflammatory diet in participants was associated with higher FLl; also DIl score was positively associated with non-invasive liver markers (ALT, AST and GGT), this suggests that diet-induced inflammation may increase liver disorders. We found a positive association between the FLI with BMI, WC and BFM in crude and adjusted models. Actually, this finding supports the idea that inflammation is induced by adiposity, but this association may be bidirectional. A positive association between DII and FLI has also been observed in the study of Cantero et al [13]; as their study has shown higher inflammation and fewer adherences to the Mediterranean diet were related with a higher degree of liver disorders in obese individuals.

In this study, the level of inflammatory markers was not measure, but given that obesity is an inflammatory condition; and the increasing in BMI is associated with an increase in DIl score $(\mathrm{Q} 1=26.97$ vs. Q4 = 27.90), thus from this finding, the association of DII with inflammatory conditions is inferred. A study by Fong et al. (2006) observed association between different diet-quality scores including the alternative healthy eating index (AHEI), healthy eating index ( $\mathrm{HEI})$ and the alternate Mediterranean diet index (aMED), with inflammatory markers such as CRP and IL-6 [24]. Sureda et al (2018) reported that low adherence to the Mediterranean dietary pattern (MDP) was directly associated with a worse profile of plasmatic inflammation markers including adiponectin, Leptin, TNF-a, plasminogen activator inhibitor 1 (PAl-1) and high-sensitivity C-reactive protein (hs-CRP) [25]. 
Our study showed that the more pro-inflammatory diet in the participants was associated with higher energy intake, red meat, saturated fat, trans fat, cholesterol, MUFA and PUFA. Previous studies have shown that healthy food is inversely related to inflammation $[1,2]$ and also several trial and metaanalysis studies have reported the association between enough intake of vitamin $C$, vitamin $E$, antioxidants and fiber with lower levels of inflammatory markers $[3,4,6,7]$. On the other hand, associations between DII and metabolic syndrome (MetS) components including high TG and low HDL-C concentrations, high blood pressure, glucose intolerance, central obesity, CVD and liver cancer have been reported [2, 26-28]. Overall, the studies mentioned and our finding consistent the hypothesis that diet an important factor in the inflammation process $[13,26]$.

In the crude and adjusted models with increasing physical activity, inflammation was reduced. A cohort study with a 10-year follow-up showed physically active participants at baseline had lower CRP and II-6 levels, and this difference remained stable over time [29]. There are other studies that have reported an inverse association of physical activity with inflammatory markers [30-32].

The liver has many functions within the body including amino acid synthesis, carbohydrate metabolism, cholesterol linkage, protein degradation, the manufacture of TG and the major part of lipoprotein synthesis [33]. Currently, there is no effective treatment for NAFLD; therefore, recently many researches have been focused to find biomarkers for prediction of liver disorders specially NAFLD. FLI is a combination of four components of BMI, WC, TG and GGT. Thus calculating the FLI is simple, and a method of accurate and cost effective [14]. According to the components of the FLI (including anthropometric measures, liver enzymes and blood lipid), its increasing can be a type of inflammation and setting an anti-inflammatory diet can keep balance the FLI.

The main strength of current study is the use of prospective study data (RaNCD); the data was collected for research purposes, and the demographic, anthropometric and biochemical data were of high quality. Large sample size was another advantage of the present study. One limitation of present study is that liver fat was not directly measured, i.e. magnetic resonance spectroscopy (MRS) or magnetic resonance imaging (MRI). Finally, the FFQ are containing some degree of measurement error, and validity of the FFQ used in RaNCD prospective study has been confirmed.

\section{Conclusion}

Our study findings showed that the more pro-inflammatory diet in participants was associated with higher FLI; also DIl score was positively associated with non-invasive liver markers (ALT, AST and GGT). We found a positive association between the FLI with BMI, WC, BFM and energy intake, red meat, saturated fat, trans fat, cholesterol, MUFA and PUFA. Therefore, it was concluded that having an antiinflammatory diet can help balance liver enzymes, reduce obesity and body fat mass and also related comorbidities like the fatty liver.

\section{Abbreviations}


AST: Aspartate transaminase; ALT:Alanine aminotransferase; BFM:Body fat mass; BMI:Body mass index; CVD:Cardiovascular disease ; CRP:C-reactive protein; DBP:diastolic blood pressure; DII:dietary inflammatory index; FFQ:Food Frequency Questionnaire; FLl:fatty liver index; GGT:gamma-glutamyltransferase; HCC:Hepatocellular cancer ; IL-1 b:Interleukin-1 b; IL-4:Interleukin-4; IL-6:Interleukin- 6; IL10:Interleukin-10; MUFA:mono-unsaturated fatty acids; NAFLD:Non-alcoholic fatty liver disease; TG:Triglycerides; TNF-a:Tumor Necrosis Factor-a; SBP:systolic blood pressure; PUFA:Poly-unsaturated fatty acids ; SFAs:Saturated fats; RaNCD:Ravansar Non-Communicable Diseases ;VFA:Visceral fat area; WC:Waist circumference; WHR:Waist hip ratio

\section{Declarations}

\section{Acknowledgments}

The authors thank the PERSIAN cohort Study collaborators and of Kermanshah University of Medical Sciences.

\section{Authors' contributions}

Yahya Pasdar designed the the study, Mitra Darbandi and Shahab Rezaeian carried out all analyses and visualization of the results. Mitra Darbandi and Azad Ayenepour drafted the manuscript with assistance from Farid Najafi, Behrooz Hamzeh and Ebrahim Shakiba. All authors provided critical input into the interpretation of the results, revisions to the manuscript and approved the final draft.

\section{Funding}

This study was supported by the Kermanshah University of Medical Sciences, Kermanshah, Iran (grant number 990617).

\section{Availability of data and materials}

The datasets used and analyzed during the current study are available from the corresponding author on reasonable request.

\section{Consent for publication}

Not applicable.

\section{Ethics approval and consent to participate}

The Ethics Committee of Kermanshah University of Medical Sciences approved the study (code: KUMS.REC.1399.640). All the participants were provided oral and written informed consent.

\section{Competing interests}

The authors declare that they have no competing interests 


\section{References}

1. Thoma C, Day CP, Trenell MI. Lifestyle interventions for the treatment of non-alcoholic fatty liver disease in adults: a systematic review. J Hepatol. 2012;56(1):255-66.

2. Zarean E, Goujani R, Rahimian G, Ahamdi A. Prevalence and risk factors of non-alcoholic fatty liver disease in southwest Iran: a population-based case-control study. Clin Exp Hepatol. 2019;5(3):224.

3. Byrne CD, Targher G. NAFLD: a multisystem disease. J hepatol. 2015;62(1):S47-S64.

4. Sanyal AJ. Past, present and future perspectives in nonalcoholic fatty liver disease. Nat Rev Gastroenterol Hepatol. 2019;16(6):377-86.

5. Asrih M, Jornayvaz FR. Inflammation as a potential link between nonalcoholic fatty liver disease and insulin resistance. J Endocrinol. 2013;218(3):R25-36.

6. Salas-Salvadó J, Garcia-Arellano A, Estruch R, Marquez-Sandoval F, Corella D, Fiol M, et al. Components of the Mediterranean-type food pattern and serum inflammatory markers among patients at high risk for cardiovascular disease. Eur J Clin Nutr. 2008;62(5):651-9.

7. Tabung FK, Steck SE, Ma Y, Liese AD, Zhang J, Caan B, et al. The association between dietary inflammatory index and risk of colorectal cancer among postmenopausal women: results from the Women's Health Initiative. Cancer Causes Control. 2015;26(3):399-408.

8. Minihane AM, Vinoy S, Russell WR, Baka A, Roche HM, Tuohy KM, et al. Low-grade inflammation, diet composition and health: current research evidence and its translation. Br J Nutr. 2015;114(7):9991012.

9. Shivappa N, Steck SE, Hurley TG, Hussey JR, Hébert JR. Designing and developing a literaturederived, population-based dietary inflammatory index. Public Health Nutr. 2014;17(8):1689-96.

10. Shivappa N, Godos J, Hébert JR, Wirth MD, Piuri G, Speciani AF, et al. Dietary inflammatory index and colorectal cancer risk-a meta-analysis. Nutrients. 2017;9(9):1043.

11. Ramallal R, Toledo E, Martinez-Gonzalez MA, Hernandez-Hernandez A, Garcia-Arellano A, Shivappa N, et al. Dietary inflammatory index and incidence of cardiovascular disease in the SUN cohort. PloS One. 2015;10(9):e0135221.

12. Shivappa N, Hebert JR, Kivimaki M, Akbaraly T. Alternative Healthy Eating Index 2010, Dietary Inflammatory Index and risk of mortality: results from the Whitehall II cohort study and meta-analysis of previous Dietary Inflammatory Index and mortality studies. Br J Nutr. 2017;118(3):210-21.

13. Cantero I, Abete I, Babio N, Arós F, Corella D, Estruch R, et al. Dietary Inflammatory Index and liver status in subjects with different adiposity levels within the PREDIMED trial. Clin Nutr. 2018;37(5):1736-43.

14. Bedogni G, Bellentani S, Miglioli L, Masutti F, Passalacqua M, Castiglione A, et al. The Fatty Liver Index: a simple and accurate predictor of hepatic steatosis in the general population. BMC gastroenterol. 2006;6(1):33.

15. Chang JW, Lee HW, Kim BK, Park JY, Ahn SH, Han K-H, et al. Hepatic Steatosis Index in the Detection of Fatty Liver in Patients with Chronic Hepatitis B Receiving Antiviral Therapy. Gut Liver. 2020:1-11. 
16. Hyysalo J, Männistö VT, Zhou Y, Arola J, Kärjä V, Leivonen M, et al. A population-based study on the prevalence of NASH using scores validated against liver histology. J Hepatol. 2014;60(4):839-46.

17. Festi D, Schiumerini R, Marzi L, Di Biase A, Mandolesi D, Montrone L, et al. the diagnosis of nonalcoholic fatty liver disease-availability and accuracy of non-invasive methods. Aliment Pharmacol Ther. 2013;37(4):392-400.

18. Yang B-L, Wu W-C, Fang K-C, Wang Y-C, Huo T-I, Huang Y-H, et al. External validation of fatty liver index for identifying ultrasonographic fatty liver in a large-scale cross-sectional study in Taiwan. PloS One. 2015;10(3):e0120443.

19. Koehler EM, Schouten JN, Hansen BE, Hofman A, Stricker BH, Janssen HL. External validation of the fatty liver index for identifying nonalcoholic fatty liver disease in a population-based study. Clin Gastroenterol Hepatol. 2013;11(9):1201-4.

20. Huang $X$, Xu M, Chen $Y$, Peng $K$, Huang $Y$, Wang $P$, et al. Validation of the fatty liver index for nonalcoholic fatty liver disease in middle-aged and elderly Chinese. Medicine. 2015;94(40).

21. Dehnavi Z, Razmpour F, Naseri MB, Nematy M, Alamdaran SA, Vatanparast HA, et al. Fatty liver index (FLI) in predicting non-alcoholic fatty liver disease (NAFLD). Hepat Mon. 2018;18(2).

22. Pasdar Y, Najafi F, Moradinazar M, Shakiba E, Karim H, Hamzeh B, et al. Cohort profile: Ravansar Non-Communicable Disease cohort study: the first cohort study in a Kurdish population. Int $\mathrm{J}$ Epidemiol. 2019;48(3):682-3f.

23. Ruiz-Canela M, Bes-Rastrollo M, Martínez-González MA. The role of dietary inflammatory index in cardiovascular disease, metabolic syndrome and mortality. Int J Mol Sci. 2016;17(8):1265.

24. Fung TT, McCullough ML, Newby P, Manson JE, Meigs JB, Rifai N, et al. Diet-quality scores and plasma concentrations of markers of inflammation and endothelial dysfunction. Am J Clin Nutr. 2005;82(1):163-73.

25. Sureda A, Bibiloni MDM, Julibert A, Bouzas C, Argelich E, Llompart I, et al. Adherence to the mediterranean diet and inflammatory markers. Nutrients. 2018;10(1):62.

26. Abdollahzad H, Pasdar Y, Nachvak SM, Rezaeian S, Saber A, Nazari R. The relationship between the dietary inflammatory index and metabolic syndrome in Ravansar cohort study. Diabetes Metab Syndr Obes. 2020;13:477.

27. Ayenehpour A, Nazar MM, Samadi M, Hamzeh B, Najafi F, Karimi S, et al. Association of Dietary Inflammatory Index with Cardiovascular Disease in Kurdish Adults: Results of a Prospective Study on Ravansar Non-Communicable Diseases. BMC Cardiovasc Disord. 2020;20:434.

28. Zhong GC, Wang K, Peng Y, Shivappa N, Hébert JR, Wu YQL, et al. Dietary inflammatory index and incidence of and death from primary liver cancer: A prospective study of 103,902 American adults. Int J Cancer. 2020.

29. Hamer M, Sabia S, Batty GD, Shipley MJ, Tabák AG, Singh-Manoux A, et al. Physical activity and inflammatory markers over 10 years: follow-up in men and women from the Whitehall II cohort study. Circulation. 2012;126(8):928-33. 
30. King DE, Carek P, Mainous 3rd AG, Pearson WS. Inflammatory markers and exercise: differences related to exercise type. Med Sci Sports Exerc. 2003;35(4):575-81.

31. Loprinzi PD, Walker JF, Lee H. Association between physical activity and inflammatory markers among US adults with chronic obstructive pulmonary disease. Am J Health Promot. 2014;29(2):81-8.

32. Yu Z, Ye X, Wang J, Qi Q, Franco OH, Rennie KL, et al. Associations of physical activity with inflammatory factors, adipocytokines, and metabolic syndrome in middle-aged and older chinese people. Circulation. 2009;119:2969-77.

33. Matos C, Porayko MK, Francisco-Ziller N, DiCecco S. Nutrition and chronic liver disease. J Clin Gastroenterol. 2002;35(5):391-7.

\section{Figures}
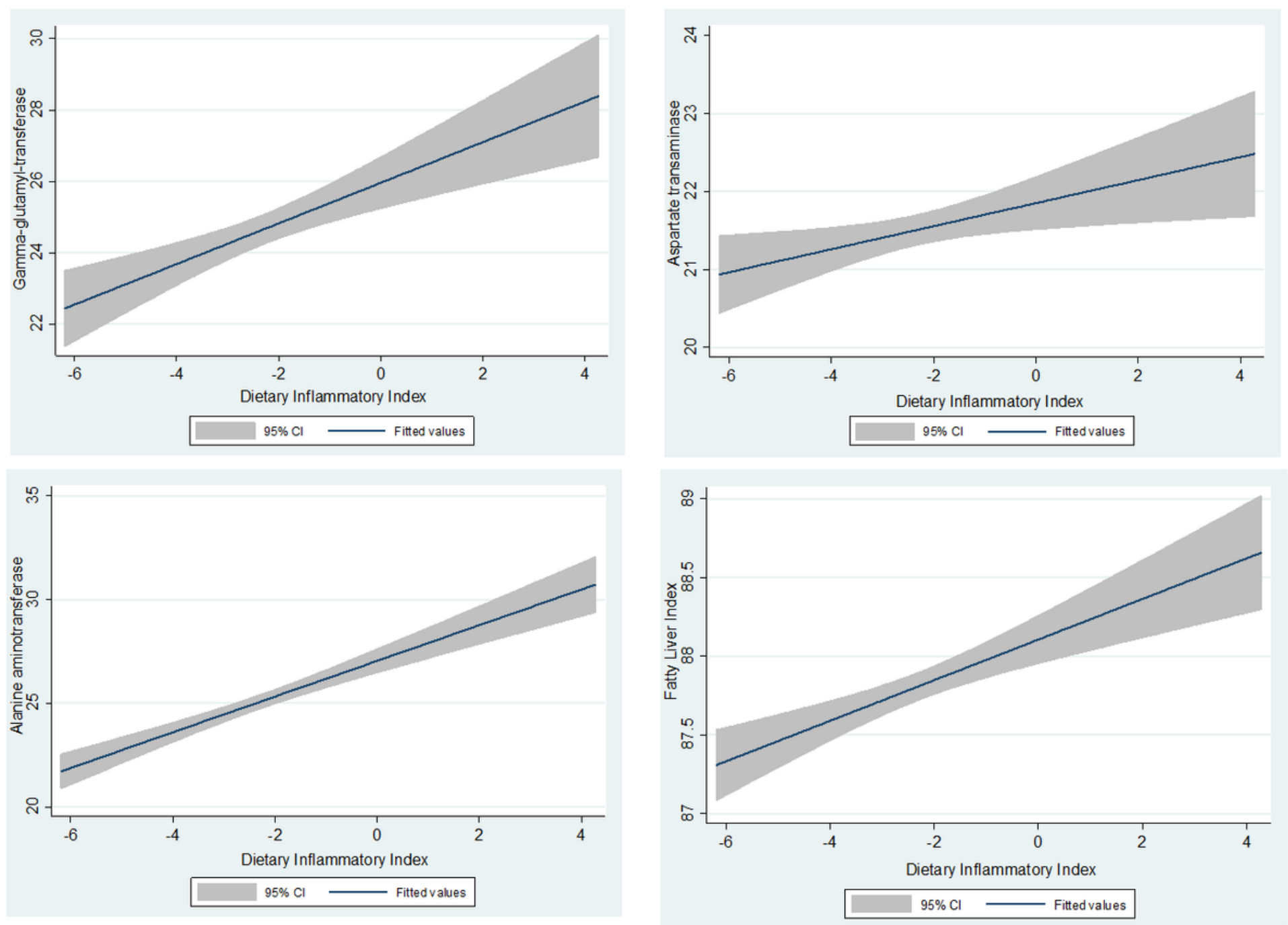

\section{Figure 1}

Associations between markers of liver status and dietary inflammatory index 